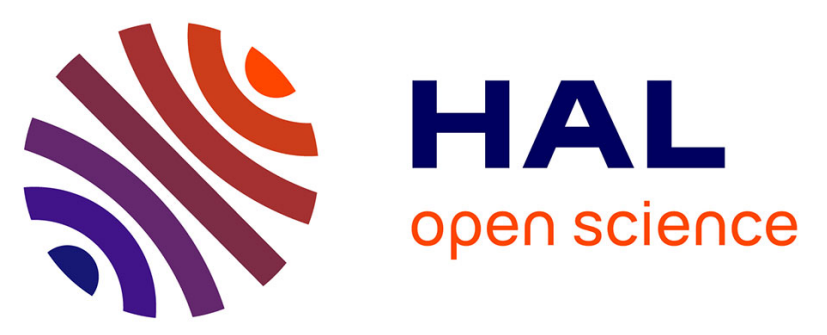

\title{
Structural characterization of antibody drug conjugate by a combination of intact, middle-up and bottom-up techniques using sheathless capillary electrophoresis - Tandem mass spectrometry as nanoESI infusion platform and separation method
}

Nassur Said, Rabah Gahoual, Lauriane Kuhn, Alain Beck, Yannis-Nicolas Francois, Emmanuelle Leize-Wagner

\section{- To cite this version:}

Nassur Said, Rabah Gahoual, Lauriane Kuhn, Alain Beck, Yannis-Nicolas Francois, et al.. Structural characterization of antibody drug conjugate by a combination of intact, middle-up and bottom-up techniques using sheathless capillary electrophoresis - Tandem mass spectrometry as nanoESI infusion platform and separation method. Analytica Chimica Acta, 2016, 918, pp.50-59. 10.1016/j.aca.2016.03.006 . hal-01981303

\author{
HAL Id: hal-01981303 \\ https://hal.science/hal-01981303
}

Submitted on 14 Jan 2019

HAL is a multi-disciplinary open access archive for the deposit and dissemination of scientific research documents, whether they are published or not. The documents may come from teaching and research institutions in France or abroad, or from public or private research centers.
L'archive ouverte pluridisciplinaire HAL, est destinée au dépôt et à la diffusion de documents scientifiques de niveau recherche, publiés ou non, émanant des établissements d'enseignement et de recherche français ou étrangers, des laboratoires publics ou privés. 


\title{
Structural characterization of antibody drug conjugate by a combination of intact, middle-up and bottom-up techniques using sheathless capillary electrophoresis - tandem mass spectrometry as nanoESI infusion platform and separation method.
}

\author{
Nassur Said ${ }^{1}$, Rabah Gahoual ${ }^{1,2}$, Lauriane $\mathrm{Kuhn}^{3}$, Alain Beck ${ }^{4}$, Yannis-Nicolas François ${ }^{1}$, Emmanuelle \\ Leize-Wagner ${ }^{1}$
}

\footnotetext{
${ }^{1}$ Laboratoire de Spectrométrie de Masse des Interactions et des Systèmes (LSMIS), UDS-CNRS UMR 7140; Université de Strasbourg; Strasbourg, France.

2 Division of BioAnalytical Chemistry, AIMMS Research Group BioMolecular Analysis, VU University Amsterdam, Amsterdam, The Netherlands

${ }_{3}^{3}$ Plateforme Protéomique Strasbourg-Esplanade, Institut de Biologie Moléculaire et Cellulaire, FRC 1589, CNRS, Université de Strasbourg, Strasbourg, France.

${ }^{4}$ Centre d’immunologie Pierre Fabre; Saint-Julien-en-Genevois, France.
}

ABSTRACT: Antibody-drug conjugates (ADCs) represent a fast growing class of biotherapeutic products. Their production leads to a distribution of species exhibiting different number of conjugated drugs overlaying the inherent complexity resulting from the monoclonal antibody format, such as glycoforms. ADCs require an additional level of characterization compared to first generation of biotherapeutics obtained through multiple analytical techniques for complete structure assessment. We report the development of complementary approaches implementing sheathless capillary electrophoresis-mass spectrometry (sheathless CE-MS) to characterize the different aspects defining the structure of brentuximab vedotin. Native MS using sheathless CE-MS instrument as a nanoESI infusion platform enabled accurate mass measurements and estimation of the average drug to antibody ratio alongside to drug load distribution. Middle-up analysis performed after limited IdeS proteolysis allowed to study independently the light chain, Fab and $F\left(a b^{\prime}\right) 2$ subunits incorporating 1, 0 to 4 and 0 to 8 payloads respectively. Finally, a CZE-ESI-MS/MS methodology was developed in order to be compatible with hydrophobic drug composing ADCs. From a single injection, complete sequence coverage could be achieved. Using the same dataset, glycosylation and drug-loaded peptides could be simultaneously identified revealing robust information regarding their respective localization and abundance. Drug-loaded peptide fragmentation mass spectra study demonstrated drug specific fragments reinforcing identification confidence, undescribed so far. Results reveal the method ability to characterize ADCs primary structure in a comprehensive manner while reducing tremendously the number of 
experiments required. Data generated showed that sheathless CZE-ESI-MS/MS characteristics position the methodology developed as a relevant alternative for comprehensive multilevel characterization of these complex biomolecules.

\section{INTRODUCTION}

Antibody-drug conjugates (ADCs) are an emerging category of biotherapeutic products, derived from monoclonal antibodies (mAbs)[1], they combine the high anti-cancer potency of cytotoxic drugs to the exquisite selectivity and favorable pharmacological properties of mAbs and are obtained through chemical linkage [2]. In addition to the recent approval by the US Food and Drugs Administration (FDA) of brentuximab vedotin (Adcentris, Seattle Genetics) and trastuzumab emtansine (Kadcyla, Genentech/ Roche), more than 50 ADCs are currently investigated in clinical trials indicating the broad interest of the biopharmaceutical industry for this type of treatments $[3,4]$. ADCs incorporate highly potent warheads which can be delivered using the specificity provided by mAbs to target tumor cells and limit exposition of healthy cells therefore optimizing treatment potency and limit the occurrence of side effects [5].

Drug conjugation can be implemented through different chemical reactions depending on the amino acid residue or glycan concerned [6]. Especially, drug coupling using the lysine residue's amino group and cysteine residues through thiol group after reduction of disulphide bridges have been reported[7, 8]. Drug conjugation reaction leads to the production of a mixture of different species showing various numbers of drugs conjugated to the protein. While for a single species, drugs can still be distributed in various manner on the different conjugation sites. This complexity is reflected by parameters such as the drug loading and distribution, the amount of naked antibody (D0) and the average number of drug to antibody (DAR). These three parameters are critical quality attributes (CQAs) for ADCs because they impact on safety, pharmacokinetics (PK) and pharmacodynamics (PD) [9].

ADCs heterogeneity generated from different number and position of conjugated drugs during production is combining to the intrinsic variability coming from conjugation with mAbs. mAbs are complex glycoproteins exhibiting a consequent number of micro-heterogeneities which can influence significantly antibody-dependent cell-mediated cytotoxicity (ADCC) and complement-dependent cytotoxicity of the considered mAb [10,11]. Currently a large panel of analytical techniques are required in order to perform a comprehensive structural characterization of biotherapeutic proteins including ADCs [12]. Mass spectrometry (MS) has gradually taken a decisive position in structure characterization of biopharmaceutical products [13-16], likewise ADCs, mainly due to an outstanding selectivity allowing the identification of the different species composing ADCs samples and the opportunity to obtain structural information [17]. MS still often needs to be used in concomitance with separation methods 
mainly including liquid chromatography $[18,19]$. Recently, we described a method using capillary zone electrophoresis (CZE) coupled to tandem MS with a sheathless interface to perform the simultaneous characterization of several aspects of a protein in one injection including amino acid sequence, glycosylation characterization and other types of posttranslational modifications (PTMs) [20-22].

In this work, we report the development of a combined approach implementing a sheathless capillary electrophoresis (CE) interface used as nanoESI infusion platform or as separation method, hyphenated to tandem MS (MS/MS) for the detailed structural characterization of different traits composing the primary structure of ADCs. The ADC considered is brentuximab vedotin (BV) which has been approved in 2011 by the FDA and consequently by the European Medicine Agency (EMA) for the treatment of Hodgkin Lymphoma and systemic anaplastic large cell lymphoma[7, 23]. It is composed of the tubulin inhibitor monomethyl auristatin E (MMAE) conjugated to the chimeric mAb cAC10 via a protease cleavable maleimidocaproyl-valine-citrulline-(( $p$-aminobenzyl)oxy)carbonyl linker (MC-PV-PABC) by reduction of the interchain disulfide bonds $[7,24]$. The presence of the cysteine linked MMAE does not disrupt the interchain disulfide bonds between the heavy chain (Hc) and (Lc) of the mAb which allows to maintain the higher order structure of the protein and therefore its specificity for the targeted antigen $[25,26]$.

As the first level of characterization, we evaluated the sheathless CE-MS system as nanoESI infusion platform for native MS determination of the average DAR of BV and to obtain the drug load distribution. In a second step, to further investigate the characterization of BV using the instrument setting, we realized the middle-up analysis of BV by IdeS proteolysis. IdeS enzymatic reaction cleaves ADC between the two consecutive glycine residues present in the hinge region to obtain two types of fragments $\left(F_{c / 2}\right.$ and $\left.F\left(a b^{\prime}\right) 2\right)$. Finally, a sheathless CE-MS/MS method derived from bottom-up proteomic analysis was developed in order to be fully compatible to the requirement of the analysis of ADCs. Analysis of BV was performed by sheathless CZE-ESI-MS/MS enabling the simultaneous characterization of the amino acid sequence of the ADC alongside to the characterization of glycoforms as well as drug-loaded peptides giving precious information regarding the drug effectively conjugated to the mAb. 


\section{MATERIALS AND METHODS}

2.1 Materials. Chemicals used were of analytical grade or high purity grade and purchased from Sigma-Aldrich (Saint Louis, MO, USA). Water used to prepare buffers and sample solutions was obtained using an ELGA purelab UHQ PS water purification system (Bucks, UK). RapiGest SF surfactant was purchased from Waters (Milford, MA, USA). IdeS (immunoglobulin degrading enzyme of Streptococcus pyogenes) also named FabRICATOR was purchased from Genovis (Lund, Sweden). Brentuximab vedotin (Adcetris ${ }^{\circledR}$ ) was produced by Millenium Pharmaceuticals/Takeda (London, UK).

2.2 Intact ADC sample preparation. Brentuximab vedotin (BV) was buffer exchanged with $200 \mathrm{mM}$ ammonium acetate buffer, pH 7.0 using Amicon centrifugal filters (cut off =10,000 Da) (Merck Millipore, Darmstadt, Germany). Six desalting step were performed at $10^{\circ} \mathrm{C}$ and $14,000 \times \mathrm{g}$ for 20 min each step. Ammonium acetate allows the native structure of proteins to be preserved and be compatible to ESI-MS.

2.3 ADC IdeS digestion. BV was cleaved in the hinge region using proteolysis by IdeS (FabriCATOR, Genovis) to obtain two $F_{c / 2}$ fragments and one $F\left(a b^{\prime}\right)_{2}$ fragment. Sample was diluted using $147.25 \mu \mathrm{L}$ of $50 \mathrm{mM}$ sodium phosphate, $150 \mathrm{mM} \mathrm{NaCl}, \mathrm{pH} 7.4$, to a final concentration of $1 \mu \mathrm{g} / \mu \mathrm{L}$. A volume of $2.25 \mu \mathrm{L}$ of IdeS (67 units $/ \mu \mathrm{L}$ ) was added to the sample which was left at $37^{\circ} \mathrm{C}$ for $30 \mathrm{~min}$. After digestion completion, sample was buffer exchanged with $200 \mathrm{mM}$ ammonium acetate buffer, $\mathrm{pH} 7.0$ using Amicon centrifugal filters (cut off $=10,000 \mathrm{Da}$ ) at $10^{\circ} \mathrm{C}$ and $14,000 \times \mathrm{g}$ for $20 \mathrm{~min}$.

2.4 In solution protein digestion. Prior to tryptic digestion, BV was cleaved by IdeS following the ADC IdeS digestion protocol. After IdeS digestion completion, sample was buffer exchanged using three desalted cycles (Amicon centrifugal filters, 10,000 cutoff) with $50 \mathrm{mM}$ ammonium bicarbonate buffer, pH 8.0 at $4^{\circ} \mathrm{C}$ and $14000 \mathrm{~g}$ for $20 \mathrm{~min}$. Theoretical concentration of $12.5 \mu \mathrm{g} / \mu \mathrm{L}$ was obtained by reducing sample volume to $10 \mu \mathrm{L}$. Sample were then diluted using $0.1 \%$ RapiGest surfactant to a final concentration of $6.25 \mu \mathrm{g} / \mu \mathrm{L}$ and heated to $40^{\circ} \mathrm{C}$ during $10 \mathrm{~min}$. Dithiothreitol (DTT) was added to the sample in order to obtain a final concentration of $25 \mathrm{mM}$. Samples were then heated to $80^{\circ} \mathrm{C}$ during $10 \mathrm{~min}$. After being cooled down to room temperature (RT), $10 \%$ of acetonitrile was added to the sample. A volume of $2 \mu \mathrm{L}$ of trypsin $(0.5 \mu \mathrm{g} / \mu \mathrm{L})$ was added to the sample which was left at room temperature for $3 \mathrm{~h}$, another volume of $2 \mu \mathrm{L}$ was added afterward. Digestion was performed overnight at $37^{\circ} \mathrm{C}$. A second reduction step was performed by addition of DTT to a final concentration of $35 \mathrm{mM}$ and heated for $45 \mathrm{~min}$ at $56^{\circ} \mathrm{C}$. Then $40 \%$ of isopropanol was added to the sample. After digestion completion, formic acid (FA) was added to a final concentration of $1 \%(v / v)$ in order to cleave the surfactant. Sample was left at RT for $2 \mathrm{~h}$. Sample was finally diluted to a final concentration in protein of $2.2 \mu \mathrm{M}$ using ammonium acetate $50 \mathrm{mM}, \mathrm{pH} 4.0$.

2.5 Capillary electrophoresis. CE experiments and NanoESI infusion experiments were performed with a CESI8000 capillary electrophoresis system from Sciex Separation (Brea, CA, USA). Bare fused-silica capillaries (total 
length $100 \mathrm{~cm} ; 30 \mu \mathrm{mi}$. d.) with characteristic porous tip on its final end on $3 \mathrm{~cm}$, a second capillary (total length $80 \mathrm{~cm} ; 50 \mu \mathrm{mi}$. d.) filled during experiments with BGE allows electric contact. New capillaries were flushed for 10 min at 75 psi (5.17 bar) with methanol, then 10 min with $0.1 \mathrm{M}$ sodium hydroxide, followed 10 min with $0.1 \mathrm{M}$ hydrochloric acid and water for 20 min also at 75 psi. Finally, the capillary was flushed 10 min at 75 psi with BGE which was $10 \%$ acetic acid. For nanoESI experiments, capillary was flushed for 5 min at 50 psi (3.45 bar) with 10\% acetic acid, then 5 min with sample. After measurement, capillary was flushed for 10 min at 50 psi (3.45 bar) with $10 \%$ acetic acid. No carry over between each measurement were observed with this method. For CE experiments, hydrodynamic injection (10 psi for $1 \mathrm{~min}$ ) corresponding to a total volume of $90 \mathrm{~nL}$ of sample injected was used. Separations were performed using a voltage of $+20 \mathrm{kV}$. For infusion experiments, sample was flushed into the capillary at 50 psi for $3 \mathrm{~min}$. The infusion was carried out by flushing sample at 5 psi for 5 min corresponding to a total volume of $245 \mathrm{~nL}$ of sample.

2.6 Mass spectrometry. For ADC peptide mapping characterization, the CESI8000 system was hyphenized to a Triple TOF 6600 mass spectrometer (Sciex, Darmstadt, Germany). The TripleTOF 6600 MS is equipped with a hybrid analyzer composed of a quadrupole followed by a time-of-flight (TOF) analyzers. ESI source parameters was set as follow: ESI voltage -1.45kV while Gas supplies (GS1 and GS2) were deactivated, source heating temperature $150^{\circ} \mathrm{C}$ and curtain gas value 4. Mass/charge $(\mathrm{m} / \mathrm{z})$ range was 100-2000 in MS and 50-2000 in MS/MS. External calibration was performed using a digest of $\beta$-galactosidase from Sigma-Aldrich (Saint-Louis, MO, USA). For ADC NanoESI infusion experiments, the CESI8000 system was coupled to a maxis 4G (Bruker Daltonics, Bremen, Germany). MS transfer parameters were optimized using the actual sample directly infused via the CE system using a pressure of 5 psi (340 mbar). Ion funnels were set at values of 300 and $400 \mathrm{Vpp}$. The electrospray voltage (capillary voltage) typically ranged from -1.2 to $-1.8 \mathrm{kV}$. Dry gas was set at $1.5 \mathrm{~L} / \mathrm{min}$ and source temperature at $180{ }^{\circ} \mathrm{C}$. Data processing was performed with DataAnalysis 4.0. Deconvolution of the mass spectra was performed on the basis of maximum entropy analysis using ESI Compass 1.3 Maximum Entropy Deconvolution Option. All spectra were calibrated by external calibration using CsI from Sigma-Aldrich (Saint-Louis, MO, USA).

2.7 MS/MS data analysis. Data obtained from the sheathless CE-MS/MS experiments were analyzed using Peakview and BioParmaView software (Sciex, San Francisco, CA). The mass tolerance allowed for search algorithm identification, for precursor ions was set to $\pm 5 \mathrm{ppm}$ and $\pm 0.05 \mathrm{Da}$ for fragmentation ions.

2.8 Drug-to-Antibody Ratio (DAR) determination. Average DAR values are calculated from the relative peak area of each peak from the charge state deconvoluted mass spectrum. Average DAR value is obtained following the equation:

$$
D A R=\frac{\sum n A_{\text {Drug }}}{\sum A_{\text {Drug }}}
$$

With $\mathrm{n}$ the number of drug loads ranging from 0 to 8. 


\section{RESULTS AND DISCUSSION}

\subsection{Average DAR determination using sheathless CE-MS Interface as a nanoESI emitter}

For the first level of the characterization of ADCs, we determined the average DAR of BV and we assessed the drug load distribution by native MS on a high resolution Q-TOF instrument using sheathless CE-MS interface as a nanoESI emitter (Figure 1-a). In a recent work, we demonstrated the suitability of sheathless CE-MS system to be used as nanoESI infusion platform [27]. Benefits of nanoESI as the lower source temperature and spraying voltage, the increase of sensitivity and the decrease of ion suppression phenomenon make this interface a particularly suitable system for biotherapeutic characterization. To achieve optimal MS resolution and sensitivity, BV was systematically desalted before infusion removing any components in the formulation buffer that can affect the stability of the spray. Within a single run of $5 \mathrm{~min}$ at a flow rate of $50 \mathrm{~nL} / \mathrm{min}$ which represent an infused sample volume of $250 \mathrm{~nL}$, we obtained a distribution of baseline resolved species of BV (Figure 1-a) with masses corresponding to the intact mAb linked with zero to eight payloads (Table S-1). Mass accuracies on intact BV using QTOF instrument is in total agreement with results reported in the literature $[15,26]$. As expected, no detection of ions corresponding to dissociated BV, referring to free drug loaded LC or Hc formed during the ionization or the ion transfer inside the mass spectrometer, were observed confirming that the combination of sheathless CE-MS interface with native MS enhances the detection of drug load species and allows to obtain the drug-load distribution. Based on charge state deconvoluted mass spectrum of intact and deglycosylated BV, average DAR value of 3.8 and 3.9 respectively were calculated using the relative quantification from the peak area of each peak and the corresponding number of drugs loaded. Obtained average DAR values are in good agreement with values described in the literature $[15,26][25]$. It demonstrated the ability of the sheathless CE-MS system used as nanoESI infusion platform to get structural information of intact BV within a single run and consuming in total less than of $3 \mu \mathrm{g}$ of ADC samples. 


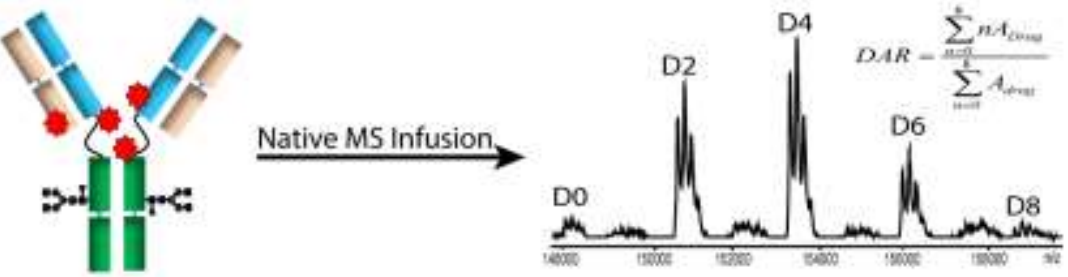

b

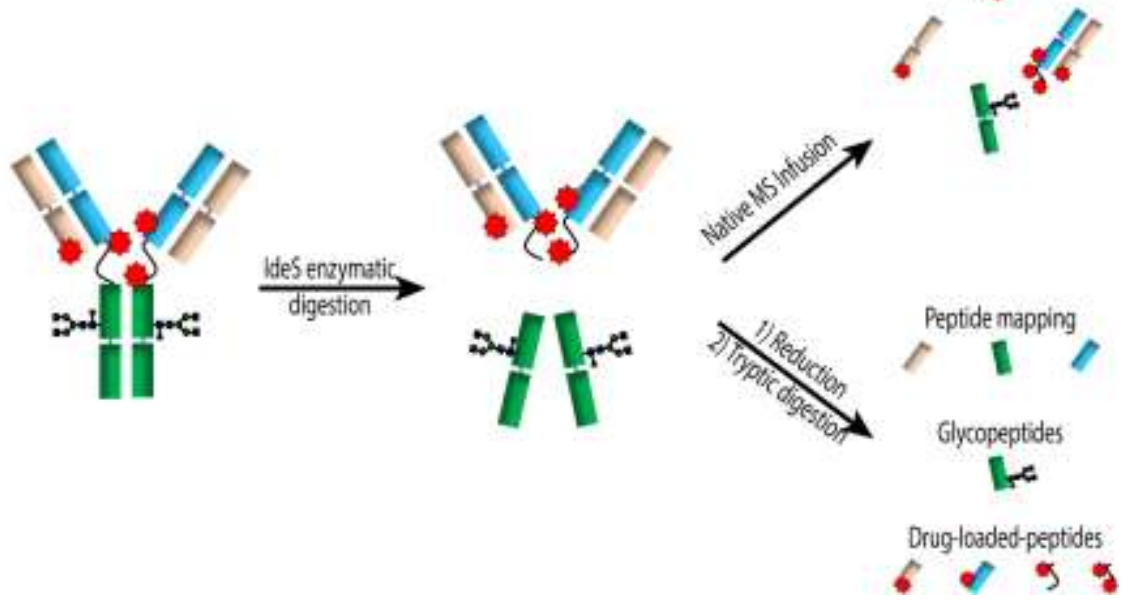

Figure 1. Overview of brentuximab vedotin structural characterization using sheathless CE-MS. (a) Native MS infusion for average DAR determination and drug loaded distribution assessment, (b) middle-up and bottom-up analysis.

\subsection{Middle-up analysis of brentuximab vedotin}

Dozens of recent reports from the FDA, Industry and academic clearly show that to extensively characterize large biopharmaceuticals such as mAbs, $A D C$, biosimilars to name a few, consistent data must be reported at multiple levels [28-36] . To investigate deeper the structure of BV using the same system, we performed the middle-up analysis of BV by IdeS proteolysis. Middle-up refers to the mass measurements of large fragments of proteins after proteolysis[29]. IdeS is a cysteine endopeptidase enzyme naturally secreted by Streptococcus pyogenes[37], IdeS enzymatic reaction cleaves specifically immunoglobulin $\mathrm{G}(\mathrm{IgG})$ between the two consecutive glycine residues present in the hinge region (Figure 1-b). IdeS cleavage results in two fragments (Figure 1-b) : $F_{c / 2}$ domain carrying a $\mathrm{N}$-glycosylation site in the Asn 297 with a mass of approximately $25 \mathrm{kDa}$ (Table S-1) depending on the glycoform and $F(a b)^{\prime} 2$ domain potentially linked by zero to eight payloads with masses of approximately $97 \mathrm{kDa}$ to $108 \mathrm{kDa}$ (Table S-1). Following the same protocol used for intact ADC, within a single run of 5 min at a flow rate of 50 $\mathrm{nL} / \mathrm{min}$, we obtained a raw MS data with three main charge envelope profiles (Figure 2-a). The resulting most intense charge envelope between $\mathrm{m} / \mathrm{z} 2000$ and 3300 (Figure 2-b) corresponds to the light chain (Lc) with the 
incorporation of one payload ( $\mathrm{Mw}=25040.1 \pm 0.1 \mathrm{Da}$ ). Of note, two glycations corresponding to a difference of mass of 162 Da were characterized (Figure 2-b1).
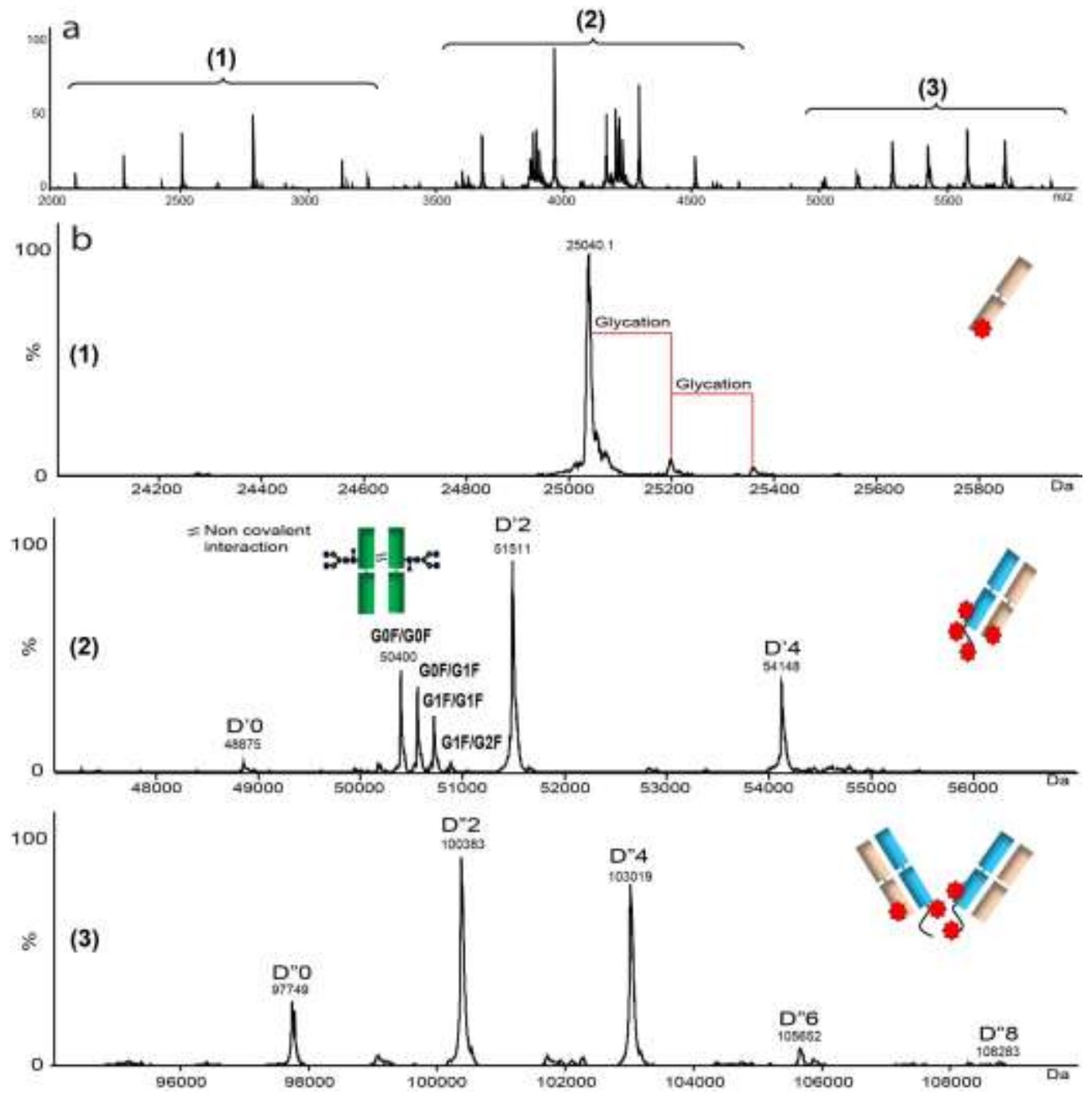

Figure 2. (a) MS spectra corresponding to Native MS NanoESI infusion of middle-up brentuximab vedotin. (b) Charge state deconvoluted mass spectra of (1) Lc-drug conjugated subunit, (2) Fab subunits with the incorporation of 0 to 4 payloads and $F_{c / 2}$ homodimers and $(c) F(a b)^{\prime} 2$ subunits with the incorporation of 0 to 8 payloads.

The second part of the raw data matching to the most intense charge envelope between $\mathrm{m} / \mathrm{z} 3500$ and 4800 corresponds to two different subunits of the BV. First, as shown in Figure 2-b2, the measured masses correspond to the Fab domain linked by zero to four payloads (Table S-1). This confirms that, even in native condition, IdeS reaction affects $\mathrm{BV}$ with the partial loss of noncovalent interaction certainly due to the hydrophobicity of the drug whose the chemical impact is greater on $100 \mathrm{kDa}$ subunits as compared to intact ADC. In second way, deconvoluted mass spectra also generated multiple masses between $50.4 \mathrm{kDa}$ to $50.8 \mathrm{kDa}$ (Figure 2-b2). These peaks correspond to the formation of protein-protein aggregates due to noncovalent interactions between $F_{c / 2}$ subunits. 
(Table S-2).
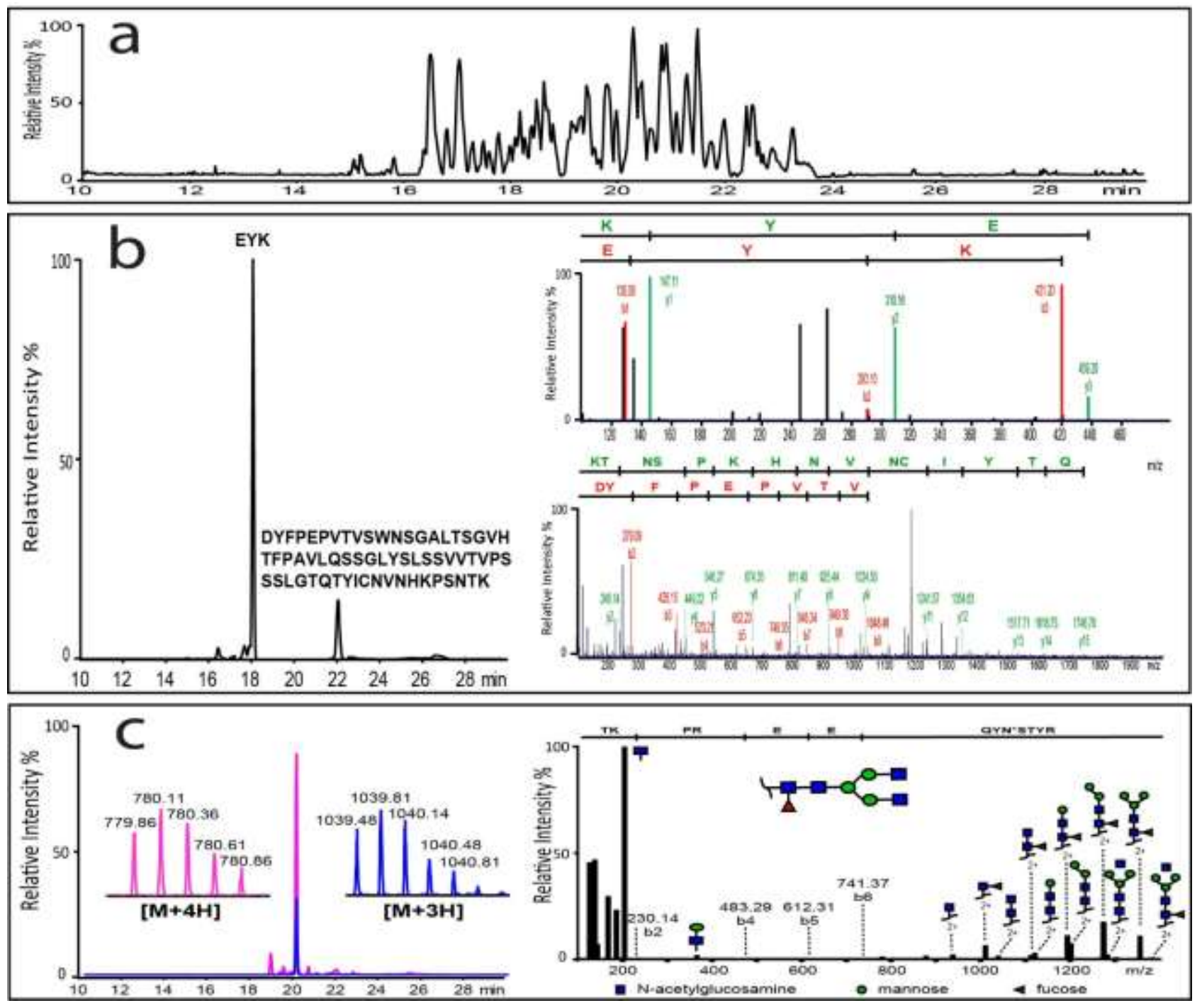

Figure 3. (a) Base Peak Electropherogram corresponding to the analysis by CESI-MS of brentuximab tryptic digest. (b) Extracted lon Electrophorogram (EIE) corresponding to the $\mathrm{m} / \mathrm{z}$ ratios of [EYK] and [DYFPEPVTVSWNSGALTSGVHTFPAVLQSSGLYSLSSVVTVPSSSLGTQTYICNVNHKPSNTK]. MS/MS fragmentation spectra for both peaks (right-hand side). (c) EIE of $\mathrm{m} / \mathrm{z}$ ratios 780.11 and 1039.81 ([TKPREEQYNSTYR] + GOF) and corresponding MS/MS fragmentation spectra (right-hand side).

Other mass peaks between $50.4 \mathrm{kDa}$ and $50.8 \mathrm{kDa}$ correspond to the expected presence of the combination of neutral glycosylation variants of this dimer (Table S-1). In addition, no deconvoluted mass spectrum have been observed at $25 \mathrm{kDa}$ that excludes the presence of free $\mathrm{F}_{\mathrm{c} / 2}$ variants in ammonium acetate $200 \mathrm{mM}$ at $\mathrm{pH}$ 7.0. To our 
knowledge, this is the first time that non-covalent dimers of $A D C F_{c / 2}$ subunits have been observed and characterized. Finally, the third profile of the raw data (Figure 2-a) corresponding to the most intense charge envelope between $\mathrm{m} / \mathrm{z} 5000$ to 6000 is in agreement with the theoretical masses of $F\left(a b^{\prime}\right) 2$ subunits with the incorporation of 0, 2, 4, 6 and 8 payloads (Figure 2-c3 and Table S-1). The profile obtained for the middle-up analysis shows that IdeS digestion generates for the same part of the protein different kind of fragments which is illustrated for example by the detection of free $L c$ and $F\left(a b^{\prime}\right) 2$ incorporating also the $L c$ of the ADC. Therefore the mixture generated from the limited digestion did not allow to estimate a satisfying DAR value justifying the intact analysis described previously. However IdeS proteolytic digestion still remains relevant in order to study specific traits defining the structure of therapeutic proteins due to the lowered and distinctive $m / z$ range, especially to evaluate the efficiency of the coupling reaction for each proteolytic fragment. Therefore MS resolution and mass accuracy is improved supported by the increase of sensitivity and the decrease of ion suppression phenomenon provided by the nanoESI infusion demonstrated the ability of the sheathless CE-MS system to obtained structural information of BV after proteolysis.

\subsection{Primary structure characterization of brentuximab vedotin.}

MS based bottom-up analysis is commonly used to determine protein amino acid sequence and to locate or quantify PTMs. For primary structure characterization (Figure 1-c), this methodology is particularly crucial in early development of therapeutic antibodies as well as during long-term life cycle management of the biopharmaceutical products [38]. As part of this work, one of the objectives was to investigate the possibility to perform robust and confident peptide mapping of BV by sheathless CZE-ESI-MS/MS.

BV was characterized in a bottom-up proteomic adapted strategy, samples were digested by trypsin using an in solution digestion protocol. Recently, we described a method using sheathless CZE-ESI-MS to perform the simultaneous characterization of several aspects of a mAb in one injection including amino acid sequence and in comitance several types of PTMs $[20,39]$. However, for the BV analysis, the intensity of some peptide signals on the electropherogram was low or non-existent due to the presence of hydrophobic drug-loaded-peptides. More recently, Janin-Bussat et al. described the first Lys-C digestion protocol for the characterization of drug-loaded-peptides of ADC by LC-MS analysis. They improved the classical protocol by several steps of reduction, fractionation, enrichment and addition of organic solvent during the digestion protocol to maintain the drug-loaded peptides in solution [18]. Taking that into account and to enhance the level of characterization especially regarding ADCs amino acid sequence, glycoforms and drug-loaded-peptides, the sample treatment was adapted for trypsin digestion while still compatible with the electrophoretic separation, and modified with the elimination of the enrichment and LC collection steps. Briefly, prior to trypsin digestion protocol, IdeS enzymatic reaction was performed to cleave BV between the two consecutive glycine residues present in the hinge region to obtain the Hc peptide 
[THTCPPCPAPELLG] which can be conjugated by one or two payloads. After IdeS digestion completion, sample was buffer exchanged against $50 \mathrm{mM}$ ammonium bicarbonate buffer, $\mathrm{pH}$ 8.0. Before trypsin digestion, 10\% of acetonitrile was added to the sample and $40 \%$ of isopropanol after digestion [18]. Sample was finally diluted to a final concentration in protein of $2.2 \mu \mathrm{M}$ using ammonium acetate $50 \mathrm{mM}, \mathrm{pH}$ 4.0. BV digests were analyzed through sheathless CZE-ESI-MS/MS with an injection volume corresponding to a quantity of $200 \mathrm{fmol}$ of digested peptides.

The total duration of the separation was less than $35 \mathrm{~min}$ and the resulting electropherogram showed that all peptides were detected between 14 to 28 min (Figure 3-a). The tremendous efficiency of CZE separation allows peak widths at half height ranging from $0.15 \mathrm{~min}$ down to $0.8 \mathrm{~min}$ representing a number of theoretical plates ranging from 200000 up to 600000 plates. Digested peptides were analyzed by MS/MS enabling to characterize in a single injection the complete sequence coverage of BV. These results confirm the absence of any detrimental effect due to the modification of the enzymatic proteolysis protocol on the amino acid sequence characterization compared to previously published results [20]. The presence of organic solvent during reduction and digestion steps did not prevent the electrophoretic separation and detection of tryptic peptides regardless of their properties. Indeed, tryptic digestion produces a heterogeneous mixture of peptides, especially with regard to their number of amino acids. The identification during the analysis of very small peptide of 3 amino acids are observed alongside to a 63 amino acids peptide having a molecular mass of 6656.29 Da (Figure 3-b). Additionally, peptide identification was based on both peptide mass measurement and fragmentation products using MS/MS spectra in order to enable unambiguous characterization. Results demonstrate the possibility to perform characterization of ADCs amino acid sequence using the sheathless CZE-ESI-MS/MS method developed advanced and using only a single injection of $200 \mathrm{fmol}$ of digested BV peptide mixture.

\subsection{Characterization of brentuximab vedotin $\mathrm{N}$-glycosylation.}

ADCs are glycosylated proteins and those glycans are naturally incorporated in the protein during secretion into the extracellular environment [6]. BV is N-glycoslylated on the Asn 297 in the $\mathrm{CH} 2$ region. The excellent ionization efficiency provided by sheathless CZE-ESI-MS allows detection of glycopeptides with significant intensities, generating good quality MS/MS identification of even lowly abundant species. N-glycosylation characterization of BV was performed using the same data sets used for peptide mapping. In the case of BV, the extracted ion electropherograms (XIE) of the $m / z$ ratio matching to the peptide TKPREEQYN ${ }^{297}$ STYR bearing 11 glycosylations were observed (Table S-2). Identifications were based on accurate mass measurement in MS1 (Figure 3-c) provided by high resolution MS and additionally fragmentation spectra. MS/MS spectra corresponding to the fragmentation of the different glycopeptides were subsequently extracted from the data. As expected with low energy collision 
induced dissociation (CID), product ions observed in MS/MS mainly correspond to the fragmentation of the glycan moiety. Very low intense $b$ ions fragment can be observed but the peptide backbone is usually preserved (Figure 3-c). All detected glycopeptides have a charge state of 3 and 4 . The similarity of the glycoforms characterization of $\mathrm{BV}$ in terms of number of glycosylation and MS/MS quality spectra as compared to the mAb characterization previously described [20], allows to conclude that the modification of the enzymatic protocol, especially the presence of acetonitrile and isopropanol did not affect the characterization of glycopeptides.
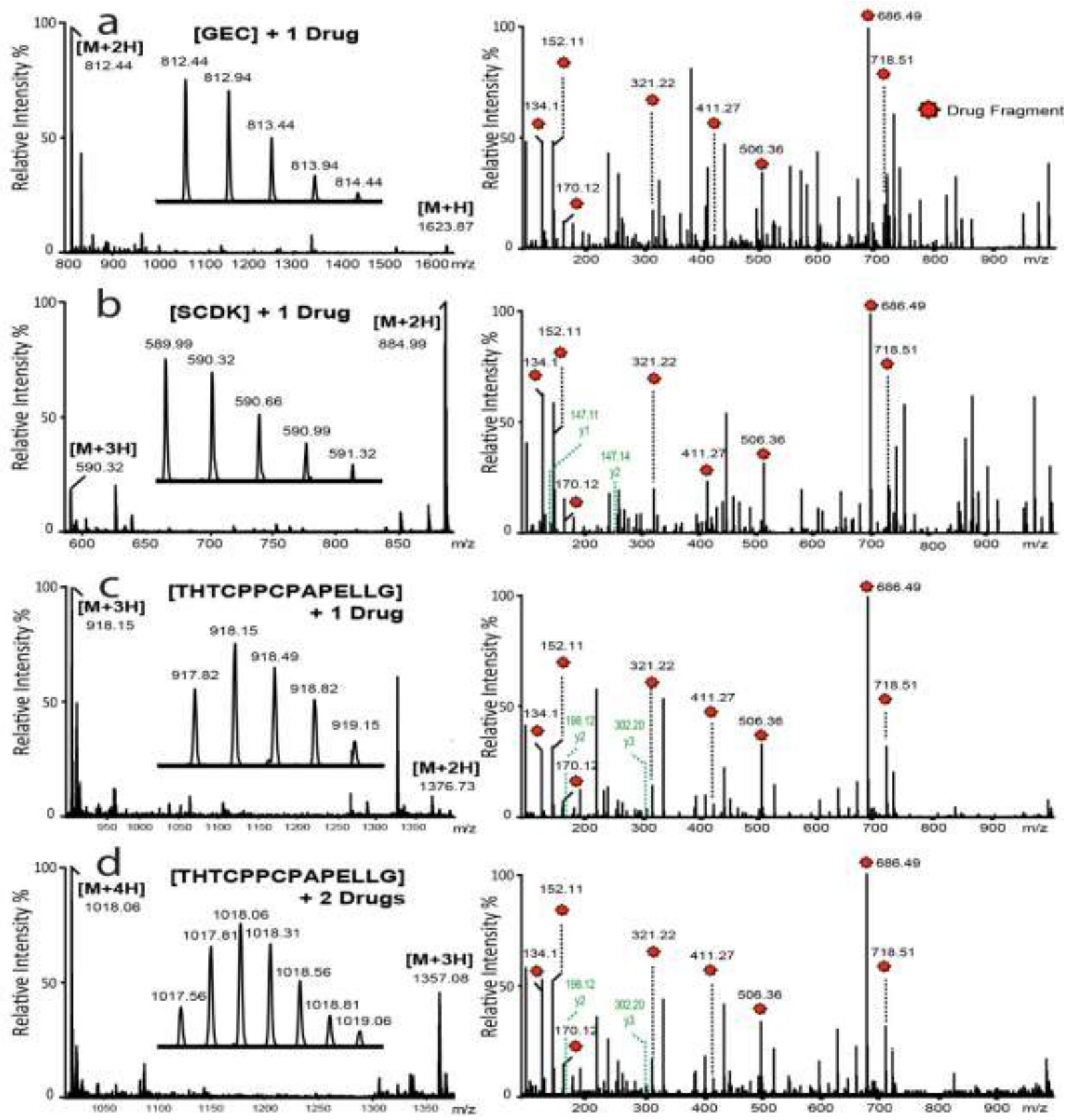

Figure 4. MS and MS/MS spectra of drug-loaded peptides. (a) [GEC] + 1 payload, (b) [SCDK] + 1 payload, (c) [THTCPPCPAPELLG] + 1 payload and (d) [THTCPPCPAPELLG] + 2 payloads 


\subsection{Identification of drug-loaded-peptide of BV}

The final aim of this work was to propose a methodology using CZE-ESI-MS/MS allowing to obtain structural information of ADCs especially regarding drug-loaded-peptides. The major issue concerning the characterization of drug-loaded-peptide is based on their hydrophobic properties because of the presence of the conjugated drug [26]. Using the protocol we developed in a previous work for the characterization of mAbs based on an aqueous solution trypsin digestion [20], no or very low intensity of these modified peptides was observed due to a possible precipitation during the reduction or digestion steps. Hydrophobic drug-loaded peptides generated from the tryptic digestion of BV could be successfully maintained in solution by incorporating acetonitrile and isopropanol in the sample preparation. These peptides could be successfully identified (Figure 4). Each peptide were characterized based on accurate mass measurement in MS1 provided by high resolution MS and additionally by the characteristic in-source fragmentation ions $(\mathrm{m} / \mathrm{z}$ 718.51) described by Junutula et al [40] and also with seven additional diagnostic ions $(m / z 686.49,506.36,411.26,321.21,170.11,152.10,134.09)$ observed in all MS/MS spectra of molecules containing MMAE (Figure 4). As glycopeptide characterization, product ions, observed in MS/MS with low energy CID, mainly correspond to the fragmentation of the MMAE moiety. Very low y ion fragment can be observed but the peptide backbone is usually preserved. However, while glycopeptide MS/MS spectra allow to detect ions corresponding to fragments of glycopeptide, drug-loaded-peptide MS/MS spectra only allow to detect the fragmentation of the drug. This makes it necessary to have a few signing ions on the MS/MS spectrum to characterize those peptides without ambiguity. The seven diagnostic ions have been identified by a molecular modeling study using Mass Spec Calculator Pro (BCP Instrument, France). Figure 5 shows the structures of MMAE fragments matching with the theoretical masses detected in all drug-loaded-peptides MS/MS spectra.

Using the same set of data, we identified four different drug-loaded-peptides. Peptides presented a [M+2H] mass of 812.44 (Figure 4-a) and a $[\mathrm{M}+2 \mathrm{H}]$ of 884.99 (Figure 4-b), were corresponding the theoretical masses of the Lc peptide [GEC] and the Hc peptide [SCDK] both conjugated to 1 payload. The peptide corresponding to $\mathrm{m} / \mathrm{z}$ 918.15 exhibiting a charge state of 3+ (Figure 4-c) was consistent to the Hc peptide [THTCPPCPAPELLG] conjugated to 1 MMAE molecule. Finally, the peptide presented a $[\mathrm{M}+4 \mathrm{H}]$ mass of 1018.06 was compatible the Hc peptide [THTCPPCPAPELLG] conjugated to 2 payloads. For [GEC] and [SCDK], Cys 218 and Cys 220 are involved in the disulfide bond with the Lc peptide and the Hc peptide respectively, while for [THTCPPCPAPELLG] Cys 226 and Cys 229 are involved in the disulfide bonds between the two $\mathrm{Hc}$. Those results confirm the characterization of the expected drug-loaded-peptides linked to the inter-chain cysteines of the Hc and Lc [18]. The capacity to separate peptides having payload is clearly interesting because they tend to compete against each other during the ionization process, potentially interfering with relative quantification. Using the sheathless CZE-ESI-MS/MS methodology, the $\mathrm{m} / \mathrm{z}$ ratios corresponding to the native peptide and the peptide incorporating 1 or 2 payloads (Table 1 ) migrate as 
two different peaks separated by several minutes. In the context of characterization of BV, results of relative quantitation allowed to estimate site by site the yield of drug incorporation (Table 1). To evaluate the robustness of this method, the analysis was repeated six times and considered as technical replicates, allowing us to obtain equivalent results. The same data were used for MS/MS peptide mapping, glycoforms and drug-loaded-peptide characterization without requiring additional experiments. Results detailed in this section clearly shows the ability using sheathless CZE-ESI-MS/MS analysis to perform a site specific localization study of the conjugation between the $\mathrm{mAb}$ and the drug employed giving additional information required in the development pipeline of ADCs therefore completing the primary structure characterization of this type of therapeutic proteins.

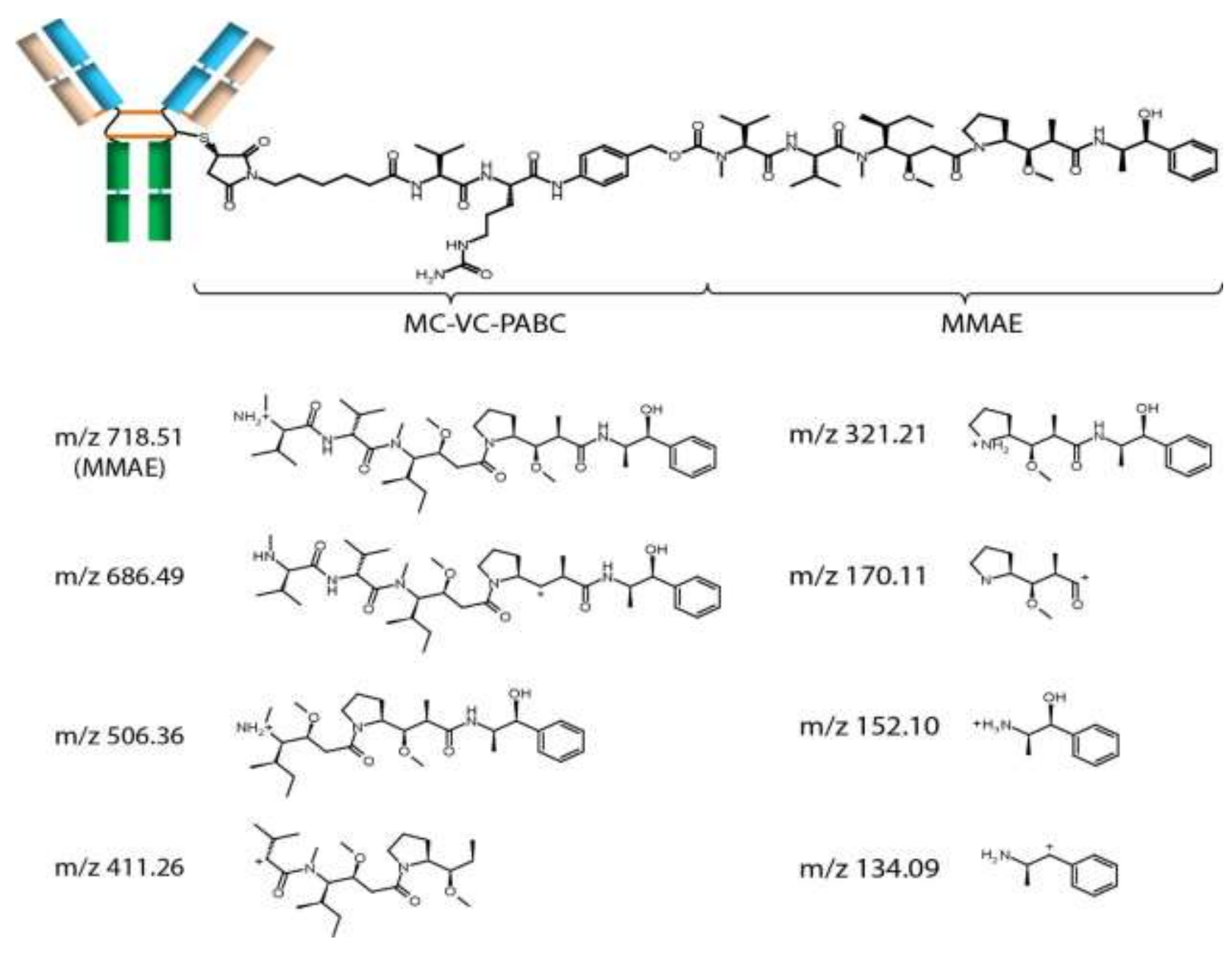

Figure 5. Schematic structures of brentuximab vedotin and characteristic fragments of MMAE payload

\section{CONCLUSION}

To summarize, we report here the implementation of new analytical approaches based on a sheathless capillary electrophoresis (CE) interface used as nanoESI infusion platform or as separation method, hyphenated to tandem MS for the detailed and rapid structural characterization of a gold standard ADC. Starting with an intact ADC native 
MS study (top level) and going through middle-up and then bottom-up MS approach, we were able to characterize $B V$ from intact mass measurement to the amino acid sequence level. At the intact $A D C$ level, we evaluated sheathless CE-MS system used as nanoESI infusion platform for native MS determination of the average DAR and drug load distribution of BV. We show native sheathless CE-MS is applicable to interchain cysteine-linked ADCs without any detrimental effect on the noncovalent structure. Within a single run of few minutes and consuming less than of $3 \mu \mathrm{g}$ BV sample, calculated DAR value were in good agreement with already published values. To investigate deeper the characterization of BV, middle-up analysis using IdeS enzymatic digestion has been performed following the same experimental protocol used for intact BV analysis. Structural information of the expected $F_{c / 2}$ subunits and $F\left(a b^{\prime}\right) 2$ subunits with the incorporation of zero to eight payloads have been obtained. Additionally, other subunits as Lc conjugated to one payload and Fab conjugated to zero to four payloads have been observed and characterized. Of note, regarding native $M S$ analysis of $F_{c / 2}$, results showed the formation of $F_{c / 2}$ non-covalent dimers following BV IdeS treatment. To the best of our knowledge, this is the first time that non-covalent dimers of $A D C F_{c / 2}$ subunits have been observed and characterized. Finally, we report here the use of sheathless CZE-ESI$\mathrm{MS} / \mathrm{MS}$ for the bottom-up analysis of BV to enhance the level of characterization, especially regarding amino acid sequence, glycoforms and drug-loaded-peptides. Using a single injection of $200 \mathrm{fmol}$, we were able to characterize the primary structure of those conjugates in a robust manner. We managed to perform the complete amino acid sequence characterization. Simultaneously, using the same set of data, glycosylations and drug-loaded-peptides were also characterized. Concerning glycosylation, 11 different $\mathrm{N}$-glycans could be characterized for BV, confirming the advantages of using sheathless CZE-ESI-MS improved sensitivity. Regarding the drug-loaded-peptides, we identified four drug-loaded-peptides linked to the inter-chain cysteines of the Hc and Lc which gave precious information regarding the localization of the conjugated drugs on the studied ADC and the assessment of the yield of drug incorporation. In order to characterize unambiguously these drug-loaded-peptides, seven diagnostic ions have been identified and structurally characterized as MMAE fragments present in MS/MS fragmentation spectra. The CZE-ESI-MS/MS data reported here indicate that electrophoretic separation, combined to the highly efficient sheathless CE-MS interface become a relevant alternative to LC-ESI-MS/MS for innovative approaches in MS for the characterization of a large panel of highly complex biotherapeutics.

\section{Acknowledgments}

Authors would like to thank Sciex separations Inc. for lending a CESI8000 system and a 5600 TripleTOF. Authors would like to thank Bruker Daltonics for lending a Maxis 4G. Authors thank Jim Thorn, Steven Lock and Dominique Mellon from Sciex separations Inc. and Yann Hebert, Pierre-Olivier Schmit and Jean-Michel Billmann from Bruker 
Daltonics for the support. The authors would like also to express their gratitude to Dr. M. Biacchi (LSMIS, Strasbourg, France), P. Hammann and J. Chicher (Institut de Biologie Moléculaire et Cellulaire, Strasbourg, France), Dr. E. Wagner-Rousset, , MC. Janin-Bussat and O. Colas (Centre d'Immunologie Pierre Fabre, St Julien en Genevois, France) for helpful discussions around antibody structural characterization by LC-MS. This work was supported by the CNRS (UMR 7140), the University of Strasbourg and a doctoral fellowship from the General Council of Mayotte to NS.

\section{References}

[1] R.V.J. Chari, Targeted cancer therapy: Conferring specificity to cytotoxic drugs, Accounts Chem. Res., 41 (2008) 98-107.

[2] S. Ornes, Antibody-drug conjugates, P. Natl. acad. Sci. USA, 110 (2013) 13695-13695.

[3] P. Sapra, B. Shor, Monoclonal antibody-based therapies in cancer: Advances and Challenges, Pharmacol. Therapeut., 138 (2013) 452-469.

[4] A. Beck, J.M. Reichert, Antibody-drug conjugates, Mabs, 6 (2014) 15-17.

[5] R.S. Zolot, S. Basu, R.P. Million, Antibody-drug conjugates, Nat. Rev. Drug Discov., 12 (2013) 259-260.

[6] A. Beck, J.F. Haeuw, T. Wurch, L. Goetsch, C. Bailly, N. Corvaia, The Next Generation of Antibody-drug Conjugates Comes of Age, Discov. Med., 53 (2010) 329-339.

[7] A. Younes, N.L. Bartlett, J.P. Leonard, D.A. Kennedy, C.M. Lynch, E.L. Sievers, A. Forero-Torres, Brentuximab Vedotin (SGN35) for Relapsed CD30-Positive Lymphomas, New Engl. J. Med., 363 (2010) 1812-1821.

[8] S. Verma, D. Miles, L. Gianni, I.E. Krop, M. Welslau, J. Baselga, M. Pegram, D.Y. Oh, V. Dieras, E. Guardino, L. Fang, M.W. Lu, S. Olsen, K. Blackwell, E.S. Grp, Trastuzumab Emtansine for HER2-Positive Advanced Breast Cancer, New Engl. J. Med., 367 (2012) 1783-1791.

[9] U. Iyer, V.J. Kadambi, Antibody drug conjugates - Trojan horses in the war on cancer, J. Pharmacol. Toxicol. Meth., 64 (2011) 207-212.

[10] S. Krapp, Y. Mimura, R. Jefferis, R. Huber, P. Sondermann, Structural analysis of human IgG-Fc glycoforms reveals a correlation between glycosylation and structural integrity, J. Mol. Biol., 325 (2003) 979-989.

[11] R. Jefferis, Recombinant antibody therapeutics: the impact of glycosylation on mechanisms of action, Trends Pharmacol. Sci., 30 (2009) 356-362.

[12] A. Beck, F. Debaene, H. Diemer, E. Wagner-Rousset, O. Colas, A.V. Dorsselaer, S. Cianférani, Cutting-edge mass spectrometry characterization of originator, biosimilar and biobetter antibodies, J Mass Spectrom., 50 (2015) 285-297.

[13] M. Biacchi, R. Gahoual, N. Said, A. Beck, E. Leize-Wagner, Y.-N. François, Glycoform Separation and Characterization of Cetuximab Variants by Middle-up Off-Line Capillary Zone Electrophoresis-UV/Electrospray Ionization-MS, Anal. Chem., 87 (2015) 6240-6250.

[14] D.R. Stoll, D.C. Hannes, J. Danforth, E. Wagner, D. Guillarme, S. Fekete, A. Beck, Direct Identification of Rituximab Main Isoforms and Subunit Analysis by Online Selective Comprehensive Two-Dimensional Liquid Chromatography-Mass Spectrometry, Anal. Chem., 87 (2015) 8307-8315.

[15] F. Debaene, A. Boeuf, E. Wagner-Rousset, O. Colas, D. Ayoub, N. Corvaia, A. Van Dorsselaer, A. Beck, S. Cianferani, Innovative Native MS Methodologies for Antibody Drug Conjugate Characterization: High Resolution Native MS and IM-MS for Average DAR and DAR Distribution Assessment, Anal. Chem., 86 (2014) 10674-10683.

[16] Y.-N. François, M. Biacchi, N. Said, C. Renard, A. Beck, R. Gahoual, E. Leize-Wagner, Characterization of cetuximab Fc/2 dimers by off-line CZE-MS, Anal. Chim. Acta, 908 (2016) 168-176.

[17] A. Beck, E. Wagner-Rousset, D. Ayoub, A. Van Dorsselaer, S. Sanglier-Cianférani, Characterization of Therapeutic Antibodies and Related Products, Anal. Chem., 85 (2013) 715-736..

[18] M.-C. Janin-Bussat, M. Dillenbourg, N. Corvaia, A. Beck, C. Klinguer-Hamour, Characterization of antibody drug conjugate positional isomers at cysteine residues by peptide mapping LC-MS analysis, J. Chromatogr. B, 981 (2015) 9-13.

[19] D. Firth, L. Bell, M. Squires, S. Estdale, C. McKee, A rapid approach for characterization of thiol-conjugated antibody-drug conjugates and calculation of drug-antibody ratio by liquid chromatography mass spectrometry, Anal. Biochem., 485 (2015) 34-42 
[20] R. Gahoual, J.-M. Busnel, A. Beck, Y.-N. François, E. Leize-Wagner, Full Antibody Primary Structure and Microvariant Characterization in a Single Injection Using Transient Isotachophoresis and Sheathless Capillary Electrophoresis-Tandem Mass Spectrometry, Anal. Chem., 86 (2014) 9074-9081.

[21] R. Gahoual, M. Biacchi, J. Chicher, L. Kuhn, P. Hammann, A. Beck, E. Leize-Wagner, Y.N. Francois, Monoclonal antibodies biosimilarity assessment using transient isotachophoresis capillary zone electrophoresis-tandem mass spectrometry, Mabs, 6 (2014) 1464-1473.

[22] R. Gahoual, A. Beck, Y.-N. François, E. Leize-Wagner, Independent highly sensitive characterization of asparagine deamidation and aspartic acid isomerization by sheathless CZE-ESI-MS/MS, J Mass Spectrom., 51 (2016) 150-158.

[23] J.A. Francisco, C.G. Cerveny, D.L. Meyer, B.J. Mixan, K. Klussman, D.F. Chace, S.X. Rejniak, K.A. Gordon, R. DeBlanc, B.E. Toki, C.L. Law, S.O. Doronina, C.B. Siegall, P.D. Senter, A.F. Wahl, cAC10-vcMMAE, an anti-CD30-monomethyl auristatin E conjugate with potent and selective antitumor activity, Blood, 102 (2003) 1458-1465.

[24] E. Oflazoglu, K.M. Kissler, E.L. Sievers, I.S. Grewal, H.P. Gerber, Combination of the anti-CD30-auristatin-E antibody-drug conjugate (SGN-35) with chemotherapy improves antitumour activity in Hodgkin lymphoma, Brit. J. Haematol., 142 (2008) 69-73.

[25] J.F. Valliere-Douglass, W.A. McFee, O. Salas-Solano, Native Intact Mass Determination of Antibodies Conjugated with Monomethyl Auristatin E and F at Interchain Cysteine Residues, Anal. Chem., 84 (2012) 2843-2849.

[26] J. Chen, S. Yin, Y. Wu, J. Ouyang, Development of a Native Nanoelectrospray Mass Spectrometry Method for Determination of the Drug-to-Antibody Ratio of Antibody-Drug Conjugates, Anal. Chem., 85 (2013) 1699-1704.

[27] R. Gahoual, J.M. Busnel, P. Wolff, Y.N. Francois, E. Leize-Wagner, Novel sheathless CE-MS interface as an original and powerful infusion platform for nanoESI study: from intact proteins to high molecular mass noncovalent complexes, Anal. Bioanal. Chem., 406 (2014) 1029-1038.

[28] B. Wang, A.C. Gucinski, D.A. Keire, L.F. Buhse, M.T. Boyne, Structural comparison of two anti-CD20 monoclonal antibody drug products using middle-down mass spectrometry, Analyst, 138 (2013) 3058-3065.

[29] Z.Q. Zhang, H. Pan, X.Y. Chen, mass spectrometry for structural characterization of therapeutic antibodies, Mass Spectrom. Rev., 28 (2009) 147-176.

[30] A. Wakankar, Y. Chen, Y. Gokarn, F.S. Jacobson, Analytical methods for physicochemical characterization of antibody drug conjugates, mAbs, 3 (2011) 161-172.

[31] S. Fekete, D. Guillarme, P. Sandra, K. Sandra, Chromatographic, Electrophoretic, and Mass Spectrometric Methods for the Analytical Characterization of Protein Biopharmaceuticals, Anal. Chem., 88(1) (2016) 480-507.

[32] Z. Kalman-Szekeres, M. Olajos, K. Ganzler, Analytical aspects of biosimilarity issues of protein drugs, J. Pharm. Biomed. Anal., 69 (2012) 185-195.

[33] L. Fornelli, D. Ayoub, K. Aizikov, A. Beck, Y.O. Tsybin, Middle-Down Analysis of Monoclonal Antibodies with Electron Transfer Dissociation Orbitrap Fourier Transform Mass Spectrometry, Anal. Chem., 86 (2014) 3005-3012.

[34] A. Beck, G. Terral, F. Debaene, E. Wagner-Rousset, J. Marcoux, M.-C. Janin-Bussat, O. Colas, A. Van Dorsselaer, S. Cianférani, Cutting-edge mass spectrometry methods for the multi-level structural characterization of antibody-drug conjugates, Expert Rev. Proteomics, 13(2) (2016) 157-183.

[35] A. Resemann, W. Jabs, A. Wiechmann, E. Wagner, O. Colas, W. Evers, E. Belau, L. Vorwerg, C. Evans, A. Beck, D. Suckau, Full validation of therapeutic antibody sequences by middle-up mass measurements and middle-down protein sequencing, mAbs, 8(2) (2016) 318-330.

[36] E.A. Redman, J.S. Mellors, J.A. Starkey, J.M. Ramsey, Characterization of Intact Antibody Drug Conjugate Variants Using Microfluidic Capillary Electrophoresis-Mass Spectrometry, Anal. Chem., 88(4) (2016) 2220-2226.

[37] K. Wenig, L. Chatwell, U. von Pawel-Rammingen, L. Bjorck, R. Huber, P. Sondermann, Structure of the streptococcal endopeptidase IdeS, a cysteine proteinase with strict specificity for IgG, P. Natl. acad. Sci. USA, 101 (2004) 17371-17376.

[38] S. Flatman, I. Alam, J. Gerard, N. Mussa, Process analytics for purification of monoclonal antibodies, J. Chromatogr. B, 848 (2007) 79-87.

[39] R. Gahoual, A. Burr, J.M. Busnel, L. Kuhn, P. Hammann, A. Beck, Y.N. Franccois, E. Leize-Wagner, Rapid and multi-level characterization of trastuzumab using sheathless capillary electrophoresis-tandem mass spectrometry, Mabs, 5 (2013) 479 490.

[40] J.R. Junutula, H. Raab, S. Clark, S. Bhakta, D.D. Leipold, S. Weir, Y. Chen, M. Simpson, S.P. Tsai, M.S. Dennis, Y. Lu, Y.G. Meng, C. Ng, J. Yang, C.C. Lee, E. Duenas, J. Gorrell, V. Katta, A. Kim, K. McDorman, K. Flagella, R. Venook, S. Ross, S.D. Spencer, W. Lee Wong, H.B. Lowman, R. Vandlen, M.X. Sliwkowski, R.H. Scheller, P. Polakis, W. Mallet, Site-specific conjugation of a cytotoxic drug to an antibody improves the therapeutic index, Nat. Biotech., 26 (2008) 925-932. 